

ISSN: $2395-1958$

IJOS 2019; 5(2): 574-576

(C) 2019 IJOS

www.orthopaper.com

Received: 19-02-2019

Accepted: 23-03-2019

\section{Dr. Anantharaman}

Associate Professor, Department of Orthopaedics, Thoothukudi Medical College, Tamil Nadu, India

Dr. Kathir Azhagan S

Senior Resident Department of Orthopaedics, Tagore Medical College, Tamil Nadu, India
Correspondence

Dr. Kathir Azhagan S

Senior Resident Department of Orthopaedics, Tagore Medical

College, Tamil Nadu, India

\section{Prospective awareness study of osteoporosis among a cohort of south Indian population}

\section{Dr. Anantharaman and Dr. Kathir Azhagan S}

DOI: $\underline{\text { https://doi.org/10.22271/ortho.2019.v5.i2h.57 }}$

\section{Abstract}

Osteoporosis is a problem worldwide, and in many countries, up to one in three women and one in five men aged 50 years or over will suffer an osteoporotic fracture. Osteoporosis causes bones to become weak and fragile, so that they break easily - even as a result of a minor fall, a bump, a sneeze, or a sudden movement. Fractures caused by osteoporosis can be life-threatening and a major cause of pain and long-term disability. Thus awareness about it is very much mandatory. Here in this study we assess the knowledge and awareness about osteoporosis among south Indian population.

Keywords: osteoporosis, awareness

\section{Introduction}

Osteoporosis is a common bone affection of the elderly characterised by low bone mass with micro architectural deterioration of bone tissue, leading to increased bone fragility resulting in increased susceptibility of fracture. Prevalence in India is high with an estimated 8 crore and 50 lakh Indians affected, much more than the entire continent of Europe. Worse is the relatively higher incidence among men and younger population than the west. Poor life style, nutritional deficiencies and lesser BMD among Indians are major contributory factors along with a low level of awareness. Above the age of 50 about $20 \%$ of women and about $10-15 \%$ of men are osteoporotic in India ${ }^{[1]}$.

Even though there is extensive literature on preventive strategies and treatment of established disease, there is still a wide gap existing in the delivery of treatment and this has been predominantly due to lack of awareness of the symptoms, causes and preventive/treatment options available. Education remains the most important preventive strategy about osteoporosis. No study till date has been performed to assess the level of awareness among the south Indian population. The base line level of knowledge of osteoporosis and its prevention in this population needs to be determined to evaluate an educational strategy.

\section{Aim}

To evaluate the awareness and knowledge of osteoporosis in a population cohort of south Indians, so as to enable a strategy for education about osteoporosis. To assess the difference in awareness amongst various group differentiated by differences in sex, age, education levels and economic status to identify target.

\section{Methods}

This was a prospective, cohort study undertaken at 2 government hospitals amongst the attenders and visitors of the in- patients of the orthopaedic department by handing over a questionnaire. The study was conducted in 2 governments medical college attached hospitals simultaneously over a period of 3 months between October 2018 to January 2019 after getting the clearance of the institutional ethical committees. The two centres of study were government Thoothukudi medical college, Thoothukudi and government Stanley medical college, Chennai. The questionnaire was translated in native language using predetermined keywords by the member conducting the study themselves on a 'as and when needed' basic assisted by the nurses chosen randomly from the wards after explaining about the study. 
A total of 150 subjects were chosen for the study from each of the centres amounting to a total of 300.The questionnaire was prepared based on the WHO guidelines on osteoporosis ${ }^{[2]}$.

Each questionnaire contained 20 questions with a set of 5 questions each equally divided into 4 sections to assess knowledge on:

1. Symptoms

2. Risk factors

3. Prevention

4. Treatment

Descriptive statistics were used to analyze the findings using the statistical package for social sciences (spss; version /2.0) for windows. Frequency distribution was used to summarize the findings for the total sample. Each group was subdivided and analysed for the above mentioned 4 criteria purely for sub grouping purposes the following criteria were used to group the study subjects into subgroups

1. Age of less than or equal to 45 was sub grouped as young

2. Subjects aged more than 45 were sub grouped as old

3. Economically subjects belonging to' below poverty line' status was sub grouped as poor.

4. Subjects above the line were sub grouped as rich

5. Education wise-subjects who have cleared class 10 level schooling were sub grouped as educated.

6. Subjects who have not cleared class 10 grade schooling were sub grouped as uneducated.

The questionnaire obtained from both the centres were merged and the evaluators were blinded to the region of the study.

\section{Inclusion criteria}

1. Healthy adults not suffering from chronic orthopaedic illness.

2. Those who are aware of the term osteoporosis.

\section{Exclusion criteria}

1. Age less than 18 or over 75

2. History of fractures

3. Treatment taken for chronic orthopaedic conditions

4. Subjects taking calcium tablets

5. Subjects with medical or allied educational qualification

6. Not walking in medical or allied profession

7. Not having mental ability to understand the questionnaire

\section{Result}

A total of 300 completed questionnaires were studied. It constituted of 124 men and 176 women. According to our criteria the subjects were classified as followed: 112 'young' and 188 'old' and 237 were 'poor' and 63 were 'rich' and finally 114 were 'uneducated' and 186 were 'educated'.

Table 1: Shows the details of the correct answers given by each subgroup of the study in summary. It shows the percentage of subjects answering 3 or more questions correctly.

\begin{tabular}{|c|c|c|c|c|c|c|}
\hline Total & Rich 67.4 & Poor 63.5 & Young 69.8 & Old 69.5 & Uneducated 56.6 & Educated 76.3 \\
\hline 1. Symptoms & $42(66.7 \%)$ & $149(62.87 \%)$ & $72(64.2 \%)$ & $126(67 \%)$ & $60(53.6 \%)$ & $133(71.5 \%)$ \\
\hline 2. Risk factors & $40(63.5 \%)$ & $144(60.7 \%)$ & $80(71.4 \%)$ & $132(70.2 \%)$ & $63(55.3 \%)$ & $150(80.6 \%)$ \\
\hline 3. Prevention & $44(69.8 \%)$ & $157(66.2 \%)$ & $79(70.5 \%)$ & $129(68.6 \%)$ & $67(58.8 \%)$ & $144(77.4 \%)$ \\
\hline 4. Treatment & $44(69.8 \%)$ & $152(64.1 \%)$ & $82(73.2 \%)$ & $136(72.3 \%)$ & $67(58.8 \%)$ & $141(75.8 \%)$ \\
\hline
\end{tabular}

Only a' yes' or 'no' where it applies is taken as a correct answer. All answers answered as 'may be' or not answered at all is marked as wrong answer.

Table 2: Shows the percentage of correct answers by subjects from all the subgroups and among the males and females.

\begin{tabular}{|c|c|c|c|c|}
\hline S No. & Questions & Answer & Male & Female \\
\hline 1 & Males & $78(26 \%)$ & $30(24.4 \%)$ & $48(27.3 \%)$ \\
\hline 2 & Increased Weight & $70(23.3 \%)$ & $29(23.4 \%)$ & $41(23.3 \%)$ \\
\hline 3 & Family history & $257(85.7 \%)$ & $104(83.9 \%)$ & $153(86.9 \%)$ \\
\hline 4 & Increased Physical activity & $180(63.7 \%)$ & $78(63.6 \%)$ & $112(63.6 \%)$ \\
\hline \multirow[t]{2}{*}{5} & Smoking & $290(26.7 \%)$ & $114(91.9 \%)$ & $176(100 \%)$ \\
\hline & How to prevent Osteoporosis & & & \\
\hline 6 & Calcium pills & $284(94.7 \%)$ & $114(91.9 \%)$ & $170(96.6 \%)$ \\
\hline 7 & Vitamin E & $64(21.33 \%)$ & $26(21 \%)$ & $38(21.6 \%)$ \\
\hline 8 & High Protein diet & $195(65 \%)$ & $79(63.7 \%)$ & $116(65.9 \%)$ \\
\hline 9 & Exercise & $238(79.3 \%)$ & $96(77.4 \%)$ & $142(80.7 \%)$ \\
\hline \multirow[t]{2}{*}{10} & Weight loss & $37(12.3 \%)$ & $14(11.2 \%)$ & $23(13.1 \%)$ \\
\hline & Symptoms of Osteoporosis & & & \\
\hline 11 & Painful bones & $274(91.3 \%)$ & $118(95.1 \%)$ & $156(88.6 \%)$ \\
\hline 12 & Fractures & $254(84.7 \%)$ & $108(87.1 \%)$ & $146(83 \%)$ \\
\hline 13 & Decreased height & $34(11.3 \%)$ & $14(11.3 \%)$ & $20(11.4 \%)$ \\
\hline 14 & Change of Posture & $44(14.7 \%)$ & $16(12.9 \%)$ & $28(15.9 \%)$ \\
\hline \multirow[t]{2}{*}{15} & Receeding gums & $192(64 \%)$ & $82(66.1 \%)$ & $110(62.5 \%)$ \\
\hline & Treatment of Osteoporosis & & & \\
\hline 16 & Sunlight & $251(83.7 \%)$ & $102(82.3 \%)$ & $149(84.7 \%)$ \\
\hline 17 & Rest & $88(29.3 \%)$ & $38(30.7 \%)$ & $50(28.4 \%)$ \\
\hline 18 & Medications & $225(75 \%)$ & $95(76.6 \%)$ & $130(73.9 \%)$ \\
\hline 19 & Hormones & $167(55.6 \%)$ & $69(55.6 \%)$ & $98(55.7 \%)$ \\
\hline 20 & Fall Prevention measures & $254(84.7 \%)$ & $102(82.3 \%)$ & $152(86.4 \%)$ \\
\hline
\end{tabular}

Among the various subgroups studied it is found that across various groups of questions overall the 'educated' subgroup comprising of subjects who have atleast cleared class 10 have fared better with a total overall percentage $76.3 \%$. Among the 
various age subgroups the overall degree of awareness of osteoporosis remains almost similar statistically $(69.8 \%$ vs $69.5 \%$ ). However there is a huge difference between the economically different subgroups with the 'rich' comprising of those subjects above the poverty line facing better in the awareness scale with $67.4 \%$ vs $63.5 \%$ awareness in the 'poor' subgroup. Amongst the various groups of questions in the questionnaire there is minimal awareness in the 'symptoms' group and that is more pronounced among the uneducated with 53.6\% only. The awareness about osteoporosis was higher amongst the female of the group overall and amongst most of the question in the questionnaire across various subgroups (14 questions amount of a total of 20 questions and 6 questions were better answered by the males of the group ${ }^{[4]}$. Our study was broadly consistent with other similar studies done across various other regions ${ }^{[3,5]}$ with previous findings in Canada ${ }^{[6]}$, Poland ${ }^{[7]}$, Turkey ${ }^{[8]}$, Sweden [9], The Czech republic ${ }^{[10]}$ and Scotland ${ }^{[11]}$.

\section{Discussion}

Epidemiological data with respect to south Indian population on prevalence of osteoporosis is lacking, and studies and data on the awareness of osteoporosis is even more so lacking. But it has been postulated by several studies that overall risk of fractures from osteoporosis is high in Indian population. Nordin reviewed 119 hip fractures [12], Gupta et al. from Kanpur analysed 425 hip fractures ${ }^{[1]}$ and found that Indian men were more commonly susceptible to hip fractures than the western counterparts. The men: women ratio is distorted because men are more likely to be brought for hospital care.

This study has shown that there are several misconceptions in regards to risk factors and symptoms of osteoporosis. Developing health awareness among the public through strategic health education could enhance the knowledge that could lead to a change in belief's and there by resulting in more preventive behaviours. Waller et al, found that subjects who had previously participated in an educational intervention consisting of information about osteoporosis risk and prevention factors scored higher in a subsequent questionnaire than those who have not attending awareness programme ${ }^{[9]}$.

This study had several limitations; first the study was performed in a orthopaedic setting where a possibility of a falsely higher scores on the questionnaire was possible consequent to a heightened sense of awareness from the environment of orthopaedic ward and staff. Therefore the sample was not representative of the entire south Indian population. Secondly the limited sample size for a bias finally the inclusion criteria is so set so as to exclude those who are totally unaware of osteoporosis thereby there is a selection bias even in choosing the study population imbedded in the study protocol itself.

\section{Conclusion}

Through this study it is concluded that awareness in key areas on osteoporosis is lacking across various subgroups of the south Indian populations and also in specific areas of knowledge and that men are in general less aware than female in key area of knowledge about osteoporosis. Targeted Health education is the key to bring about awareness to the overall population.

\section{References}

1. Gupta AK, Samuel KC, Kurian PM, Rallan RC. Preliminary study of the incidence and aetiology of femoral neck fracture in Indians. Indian J Med Res. 1967; $55: 1341-8$

2. WHO. Scientific group on the Prevention and management of osteoporosis (Geneva, Switzerland), 2000.

3. Prevention and management of osteoporosis: report of a WHO Scientific group (WHO Technical report series; 921).

4. Haddock L. Prevalence of osteopenia and osteoporosis in a normal female Puerto Rican population. P R Health Sci J. 1997; 16:241-244.

5. Doheny MO, Sedlak CA, Estok PJ, Zeller R. Osteoporosis knowledge, health beliefs, and DXA Tscores in men and women 50 years of age and older. Orthopaedic Nursing. 2007; 26:243-250.

6. Juby AG, Davis P. A prospective evolution of the awareness, knowledge, risk factors and current treatment of osteoporosis in cohort of elderly subjects. Osteoporosis Int. 2001; 12:617-622.

7. Drozdzowska B, Pluskiewicz W, Skiba M. Knowledge about Osteoporosis in a cohort of polish females: the influence of age, level of education and personal experience. Osteoporos Int. 2004; 15:645-648.

8. Unagan M, Tumer M, Turkish women's knowledge of osteoporosis. Fam Pract. 2001; 18:199-203.

9. Waller J, Ericksons O, Foldevi M, Grahn kronhed AC, Larsson L et al. Prev Med. 2002; 34:485-481.

10. Vytrisalova M, Kubena A, Vleck J, Palicka V, Hala T, Pavelka K. Knowled of osteoporosis correlated with hormone replacement therapy use and health status. Mauritas. 2007; 56:21-29.

11. Lewin KJ, Sinclair HK, Bond CM. Women's knowledge of attitude towards the hormone replacement therapy. Fam Pract. 2003; 20:112-119. 